\title{
Petersen Hernia, The Phoenix Rising Again: A Case Report
}

\author{
Rohit Thakur ${ }^{1}$, Amar Verma ${ }^{2}$, Ramesh Bharti ${ }^{3}$, Rajesh Sharma ${ }^{4}$, Ankit Shukla ${ }^{5}$, Rajesh Chaudhary ${ }^{6 *}$ \\ ${ }^{1}$ MBBS, Junior Resident, Department of Surgery, Dr. R.P. Govt. Medical College Kangra at Tanda HP, India
}

${ }^{2}$ MS, Associate Professor, Department of Surgery, Dr. R.P. Govt. Medical College Kangra at Tanda HP, India

${ }^{3}$ MS, Professor, Department of Surgery, Dr. R.P. Govt. Medical College Kangra at Tanda HP, India

${ }^{4}$ MS, Senior Resident, Department of Surgery, Dr. R.P. Govt. Medical College Kangra at Tanda HP, India

${ }^{5}$ DNB, General Surgeon, Civil Hospital Palampur, HP, India

${ }^{6}$ MS, Senior Resident, Department of Surgery, Dr. R.P. Govt. Medical College Kangra at Tanda HP, India

Received: May 16, 2018; Published: July 09, 2018

*Corresponding author: Dr. Rajesh Chaudhary, MS, Senior Resident, Department of Surgery,RP Govt. Medical College Kangra at Tanda HP, India, Email ID: topgun.chaudhary@gmail.com

\section{Abstract}

Introduction:Petersen hernia was described in patients undergoing gastrojejunostomy (GJ) for any cause. They are seen more commonly after bariatric surgery these days. Patients usually present with features of intestinal obstruction.

Case presentation: A 68-year-old man presented with the features of intestinal obstruction for 48 hours. Patient was subjected to exploratory laparotomy. He had nearly three fourth of his small gut herniated behind the gastrojejunostomy. The bowel was found viable during laparotomy which was reduced free and the defect was closed.

Conclusion: Petersen Hernia was once rare, but we are going to see more of these soon since laparoscopic bariatric surgery is on a rise

Keywords: Bariatric surgery; Intestinal obstruction; Petersen Hernia; Internal hernia

\section{Introduction}

Petersen hernia is a rare variety of internal hernia where the small gut loops herniate behind the gastrojejunostomy (GJ) site through the Petersen's space named after the surgeon who first described it [1]. The incidence of these hernia is somewhere between 1-4\% after laparoscopic surgeries but less than $1 \%$ after open bariatric surgery [2]. In the past when gastrojejunostomies were done for peptic ulcer disease this condition was seen more often, but the incidence was low. The advent and popularity of bariatric surgery has again brought this hernia into limelight.

This condition is seen more commonly after laparoscopic bariatric surgeries where the sudden loss of mesenteric fat makes the loops to herniate through the Petersen's space [3].Patients usually have a history of repeated episodes of upper abdominal pain with nausea until they develop complete intestinal obstruction one day. Contrast Enhanced Computerised Tomogram Scan (CECT) of the abdomen is the preferredradiological diagnostic tool but still it can miss the diagnosis and the issue is best settled during laparotomy where the small gut loops are seen traversing behind the GJ from left to right [4].Early surgery is required. The intestine may be strangulated requiring resection of the small gut, sometime massive gut resections requiring transplantation. We present here a case of a male patient who presented with the features of intestinal obstruction, 27 years after undergoing gastrojejunostomy for peptic ulcer disease.

\section{Case Presentation}

A 68-year-old male presented to the emergency room (ER) with two days history of pain abdomen and distension of upper abdomen. The pain was sudden in onset,colicky in nature. There was a history of similar complaints in the past. But they relieved on their own after conservative management. There was a history of some surgery done about 27 years back for perforated peptic ulcer, although there were no records available. His abdomen was distended with visible peristaltic gut loops. There was an upper midline scar of about 10-12 centimetres(CM) over the abdomen. There was mild tenderness over the whole abdomen. He was slightly dehydrated.

Pulse rate was 98 beats per minute. Blood pressure was $102 / 60 \mathrm{~mm}$ of $\mathrm{Hg}$ (millimetres of mercury). On nasogastric tube insertion about $600 \mathrm{ml}$ (millilitre) fluid was aspirated. The $\mathrm{X}$ - ray examination of abdomen showed multiple air fluid levels 
in erect film (Figure 1). His total leucocytes count was 11200/ $\mathrm{mm}^{3}$ (Per cubic millimetre). Blood urea nitrogen (BUN) was $28 \mathrm{mg} / \mathrm{dl}$, serum creatinine was $1.3 \mathrm{mg} / \mathrm{dl}$. Other biochemical and haematological parameters were within normal range. Sonological examination of the abdomen showed multiple dilated small gut loops with a maximum diameter of about $3.2 \mathrm{~cm}$, showing to and from movement of the echogenic fluid within the lumen, and minimal free fluid in the abdominal cavity.

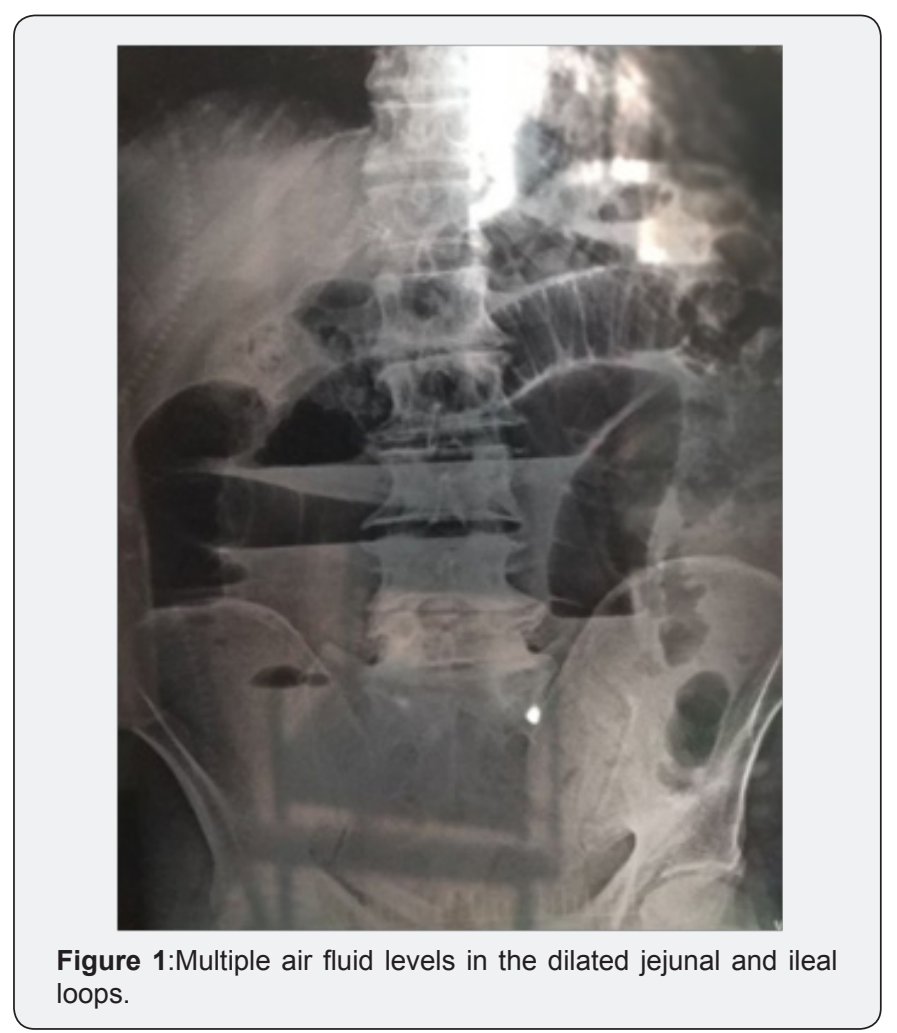

A diagnosis of acute intestinal obstruction was made, and patient was taken up for explorative laparotomy after adequate fluid resuscitation. On opening the abdomen there were multiple dilated small gut loops filled with gas and fluid. The duodena jejunal junction (DJ) was distended and about $5 \mathrm{~cm}$ from the DJ there was an intact gastrojejunostomy (GJ). About 3 feet distal to the DJ small gut has herniated under the GJ and whole of the distal jejunum and ileum was collapsed up to the ileo cecal junction (ICJ). The entrapped jejunal loop was gently retrieved (Figure 2).There was a constriction ring formed over the jejunum where it was entrapped under the GJ, although the small gut was healthy.After ensuring the viability of the small gut the mesenteric defect was closed with a running polydiaxonone suture. The patient was discharged home on fourth postoperative day and has recovered well after surgery. The patient is still under follow-up.

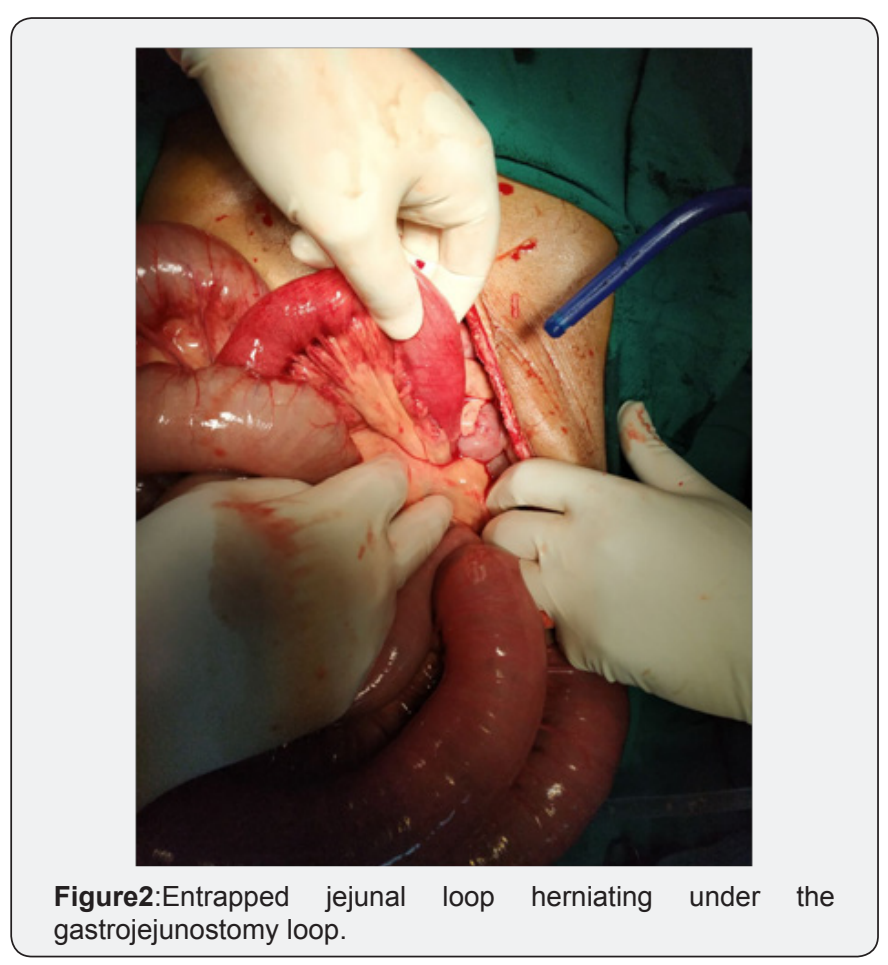

\section{Discussion}

Every surgeon in theemergency room(ER) will come across a case of acute intestinal obstruction on a day to day basis. Adhesions account for about $75 \%$ of all the cases. Next in list are the hernias followed by other rare causes. Among hernias internal hernias are a rare cause of small bowel obstruction (SBO) [5]. Petersen hernia is further a very rare form of internal hernia. It was first described by a German surgeon, Walther Petersen in 1900. It is an internal hernia seen after GJ formed for any reason. Its boundaries are described as transverse mesocolon, retroperitoneum and the mesentery of the Roux limb. There is a potential space formed behind the GJ called Petersen space through which the small gut loops herniate from left to right [1]. They were commonly seen about 50 years ago when the routine surgeries for peptic ulcer disease were performed. Peptic ulcer disease was treated with truncal vagotomy and enterectomy with drainage procedures like gastro jejunostomy. But then came an era of pharmacological advance with the development of antihistamines like Ranitidine followed by the development of Proton Pump Inhibitors (PPI).

During this time these surgeries became almost extinct and the Petersen hernia decreased dramatically. Surgeons of today's era are not well trained in all those surgeries of the past. But this entity has again made a resurgence. This is mainly due to an increase in bariatric procedures [2]. Petersen hernia is seen more commonly with laparoscopic Roux- en-Y gastric bypass 
(LRYGB). There are two or three potential hernia spaces formed after these procedures. Open surgery leads to formation of dense adhesions which keeps the incidence of Petersen hernia to as low as $1 \%$. But laparoscopic surgery is associated with lesser adhesion formation thus permitting more hernias ranging from $1-4 \%[2]$.

The patients undergoing bariatric surgery lose weight suddenly making the mesenteric fat content low thus leading to enlargement of the mesenteric defects and thus a higher incidence of this hernia [3]. The loops herniate many a times and may reduce spontaneously thus the patients present with a repeated history of upper abdominal pain and distension. but one day the loop will get stuck and not reduce spontaneously. The patients now may present with above mentioned symptoms in addition to vomiting. If the loops are not reduced at this stage the patient may develop gut strangulation.This time the patient will have extreme abdominal tenderness, bloody vomitus, tachycardia, hypotension [6].

It is difficult to reach the diagnosis of Petersen Hernia before surgery but if the patient's condition permits, Contrast Enhanced Computerised Tomogram (CECT) of abdomen may help the diagnosis. The CECT findings which point towards a diagnosis of Petersen's Hernia are: distended gut loops in the upper abdomen, displacement of ligament of Treitz anteriorly and towards right, mesenteric whirl sign, presence of small gut loops above the transverse colon or GJ, mesenteric fat stranding and distal ileum coursing towards left hypochondrium[4]. But even after this the diagnosis is only confirmed at laparotomy in around $20-30 \%$ cases [7]. Exploratory laparotomy and careful reduction of the entrapped segments by open or laparoscopic surgery is the treatment of choice as an undue delay in surgery can lead to strangulation of the entrapped gut loops worsening the prognosis. The mesenteric defects should be closed with running sutures. If delayed, patients may end up with major resections and sometimes, even require gut transplant which is generally not available at every centre [4].

\section{Conclusion}

Petersen hernia is a forgotten diagnosis which has made a resurgence with the increase in bariatric and laparoscopic procedures. A high index of suspicion and an early exploratory laparotomy may prevent the fatal outcome in a patient.

\section{References}

1. Petersen W (1900) Ueber darmveschlingung nach der gastroenterostomie. Arch Klin Chir 62: 94-114.

2. Faria G, Preto J, Oliveira M, Pimenta T, Baptista M, et al. (2011) Petersen's space hernia: A rare but expanding diagnosis. Int J Surg Case Rep 2(6): 141-143.

3. Junior AM, Scheibe CL, Campelo GP, Lima RC, Murad LM, et al. (2015) Fixing jejunal maneuver to prevent petersen hernia in gastric bypass. Arq Bras Cir Dig 28(Supl 1): 69-72.

4. Reiss JE, Garg VK (2014) Bowel gangrene from strangulated Petersen's space hernia after gastric bypass. J Emerg Med 46(2): e31-e34.

5. Kim SY, Morris JB (2007) Small bowel obstruction. In: Yeo CJ, Dempsey DT, Klein AS, Pemberton JH, Peters JH (Eds.), (6 $6^{\text {th }}$ edn), Chapter 30, Shackelford's Surgery of the Alimentary Tract, WB Saunders Company, Philadelphia, USA.

6. Gudbrand C, Andreasen LA, Boilesen AE (2015) Internal Hernia in Pregnant Women After Gastric Bypass: A Retrospective Register-Based Cohort Study. Obes Sur 25(12): 2257-2262.

7. Parakh S, Soto E, Merola S (2007) Diagnosis and management of internal hernias after laparoscopic gastric bypass. Obes Surg 17(11): 1498-1502.

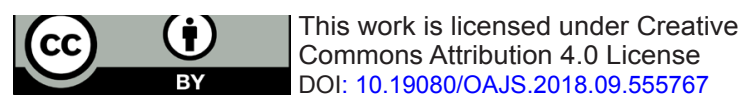

Your next submission with Juniper Publishers
will reach you the below assets
- Quality Editorial service
- Swift Peer Review
- Reprints availability
- E-prints Service
- Manuscript Podcast for convenient understanding
- Global attainment for your research
- Manuscript accessibility in different formats
( Pdf, E-pub, Full Text, Audio)
- Unceasing customer service
Track the below URL for one-step submission
https://juniperpublishers.com/online-submission.php

